ISSN $0258-7122$

Bangladesh J. Agril. Res. 32(3) : 473-486, September 20

\title{
PARTICIPATORY VARIETY SELECTION IN WHEAT AND ITS IMPACT ON SCALING-UP SEED DISSEMINATION AND VARIETAL DIVERSITY
}

\author{
D. B. Pandit ${ }^{1}$ M.M. Islam ${ }^{2}$, M.Harun-UR-Rashid ${ }^{3}$ and M.A. Sufian ${ }^{4}$
}

\begin{abstract}
Participatory selection was conducted at the Wheat Research Centre, Bangladesh Agricultural Research Institute (BARI), Dinajpur to facilitate farmers in selecting and disseminating their preferable variety and replace widely cultivated disease susceptible Kanchan to increase wheat yield and production. Farmers' need for wheat variety was identified through participatory rural appraisal in 2002 and impacts were assessed by house hold level survey in 2005. Researches were conducted as mother and baby trials. Scaling-up seed dissemination was carried out through seed supply. BAW1008, Shatabdi, and BAW 1006 produced higher yield in both mother and baby trials and got higher scores for farmers' overall preference. The farmers emphasized on yield together with bold and white grains, more grains/spike, strong stem and other characters during scoring. They identified BAW 966, BAW 1006, BAW 1008, and Shatabdi for good Chapati quality. They expected to cultivate BAW1008, Shatabdi, and BAW 1006 in the following years. Farmer to farmer seed dissemination was highly satisfactory and seeds of Shatabdi reached $47 \%$ wheat farmers of the villages in 2004-05. Varietal diversity was increased remarkably and seven varieties were grown in the study villages. The area of Kanchan came down from $100 \%$ (in 2002-03) to $24 \%$ (in 2005-06). The participating personnel were hopeful to the new concept of plant breeding and expecting its widespread use in the country.
\end{abstract}

Key Words: Wheat, participatory variety selection (PVS), mother trial (MT), baby trial (BT), seed dissemination, varietal diversity .

\section{Introduction}

Wheat is the second important cereal crop in Bangladesh. Current requirement of wheat in the country is 3.0-3.5 million tons; and its consumption is increasing @ $3 \%$ per year (Sufian, 2005). But, wheat area and production are reducing every year due to competition with high yielding boro rice, maize, potato, and vegetable crops. Yield is also decreasing from 2003-04 mainly due to cultivation of old disease susceptible Kanchan variety in most of the wheat growing areas and shifting of wheat cultivation to more marginal lands (Sufian, 2005). In this

\footnotetext{
${ }^{1-4}$ Wheat Research Centre, BARI, Nashipur, Dinajpur, Bangladesh.
} 
situation, it is very important to increase wheat yield and production in the country through use of appropriate variety. Wheat Research Centre (WRC) of Bangladesh Agricultural Research Institute (BARI) has released 24 varieties developed by traditional breeding approach and many of those are better than Kanchan (Rashid et al., 2004) in yield and other characters under research managed conditions. But those varieties are not being adopted by the farmers in a satisfactory rate, probably due to improper selection situation (on-station) that does not fit well with farmers' growing conditions, inadequate knowledge of the farmers about the varieties, lack of specifically adapted varieties and some other unknown causes.

Participatory Variety Selection (PVS) can effectively be used to identify farmer-acceptable varieties and thereby overcome the constraints that cause farmers to grow old or obsolete varieties (Joshi \& Witcombe, 1996; Witcombe et al., 1996). Moreover, participatory research increases the job efficiency of the scientists (Bellon, 2001) and farmers' knowledge that enables to be retained effectively from year to year (Grisley \& Shamambo, 1993). Research costs can be reduced and adoption rates increased if farmers are allowed to participate in variety testing and selection (Joshi et al., 1995). In addition, production increases when farmers adopt new varieties identified in participatory research (Witcombe, 1999).

Participatory Variety Selection (PVS) research was initiated at the WRC, BARI, Bangladesh in 2002 to involve the farmers in selecting their preferable varieties according to their socio-economic needs and disseminate those in noble ways so that the farmers can harvest the benefit of new varieties without delay.

\section{Materials and Method}

\section{Site description}

The experiments were conduced in greater Dinajpur, the major wheat growing district and covering about $21 \%$ wheat areas of the country. The climate of the district is suitable for wheat cultivation due to its comparatively cool and long winter. But, the soil is sandy-loam and reaction is strongly acidic $\left(\mathrm{p}^{\mathrm{H}}\right.$ ranges from 4.5 to 5.5). Fertility of the soil is poor and organic matter contents is $<1.0 \%$. The soil is already deficient in $\mathrm{N}, \mathrm{P}, \mathrm{K}, \mathrm{S}, \mathrm{B}$, and $\mathrm{Zn}$ and becoming deficient in Mo and $\mathrm{Mg}$ (Bodruzzaman et al., 2004). Moreover, foggy weather sometimes continuously prevails for $>15$ days that limits sunlight during anthesis to grain filling stages of the crop and enhances spikelets sterility. 


\section{Identify farmer's need}

Farmers' need in a variety was identified by participatory rural appraisal (PRA), conducted in 2002. A 12-member team was formed with scientists from different disciplines, extension and NGO personnel, headed by an Economist. This team with randomly selected 25 farmers irrespective of wealth, caste and sex conducted PRA to collect base line information in relation to present situation, major constraints and future needs of wheat as well as agriculture of the area.

\section{Search for suitable genotypes}

Cultivars were searched according to the needs of the farmers of study areas with some other characters, such as earliness, high yield, Bipolaris leaf blight (BpLB) tolerance, bold and white grains, good Chapati making quality, etc. On the basis of those characters, eight genotypes were selected from WRC local and exotic stocks for testing in farmers' fields in 2002-03. Five of those were unreleased varieties, one was a released variety (Shatabdi), one was check variety (Kanchan) and other two were exotic germplasm introduced from Nepal. In the next years, some genotypes were changed according to farmers' preference and seven advance lines were tested with the check variety Kanchan.

\section{Experimentation in farmers' fields}

Researches were conducted as mother trials (MT) at on-station and farmers' fields, and baby trials (BT) at farmers' fields only. Experiments were conducted at two villages in 2002-03. One more village was added in 2003-04. There were three MT in 2002-03 and two MT in 2003-04 and 2004-05 per village. There was one MT at on-station every year with 3 replications. Eight genotypes including Kanchan as a check variety were tested in MT. Released variety Shatabdi was tested in first two years. Each MT at farmer's field was considered as a single dispersed replication; therefore, there was different randomization. Mother trials were designed by researchers and quantitative data were also taken by the researchers. However, the trials were evaluated by 30 farmers per village at physiological maturity and after harvest. Scoring was done for each character as well as for overall preference. Score was from 1 to 8 . Score 8 was for the best and 1 was for the worst genotype. Research, extension and NGO personnel assisted farmers during scoring. The crop was grown with farmers' management at farmers' fields and under recommended management at on-station.

There were changes in the designs of baby trials every year. In 2002-03, seven test entries were evaluated with local check at four farmers' (replications) fields. This number of replication was quite low due to lack of seeds. In 2003-04, 
seven test entries were compared with check variety in design II method (Witcombe, 2002) with 15 replications (farmers). In 2004-05, only two genotypes, ranked $1^{\text {st }}$ and $2^{\text {nd }}$ in farmers' overall preference (FOP) score in previous year's MT, were tested in design 1 method (one testy entry and one check comprised a BT) with 30 replications (in 30 farmers' fields). Baby trials were evaluated by house hold level questionnaire (HLQ) suggested by Witcombe, 2002. Yield data were taken by the researchers. The crop was grown under farmers' management.

\section{Scaling-up seed dissemination}

Seed of farmers'-preferred released variety Shatabdi were supplied to 10 farmers of each of two villages in 2002-03 and at $3^{\text {rd }}$ village in 2003-04 for scaling up seed dissemination. Seeds were not given to the farmers in the same villages $2^{\text {nd }}$ time by the researchers. From second years, seeds were disseminated from farmers to farmers. In addition, filed days, workshops, rallies, seminars, focus group discussions (FGD), publications in mass media, etc. were done to scaling up awareness.

\section{Impact assessment}

Impacts were assessed in 2005 by a team of researchers, extension and NGO personnel headed by a $3^{\text {rd }}$ person--an Economist who was not involved with PVS activity. Impact assessment data were collected from 30 farmers from each of the three villages by the members. The criteria for selecting 30 farmers were as follows:

1. ten farmers were from PVS research collaborators;

2. ten farmers were not PVS research collaborators but got training/demonstration on wheat;

3. the rest 10 farmers were new to the researchers and did not get any training/demonstration.

There were 5-8 female in the group of 30 selected farmers. The farmers were randomly selected irrespective of wealth, religion, and caste. A house hold level questionnaire (HLQ) was prepared to record the data emphasizing new variety adoption, seed dissemination, and varietal diversity. The questionnaire was filledup by the members of the team separately. 


\section{Statistical analysis}

Every year, the least preferred entries were rejected from the mother and baby trials. However, six entries were common in two years both at farmers' field and on-station. The data of those entries were analyzed by RCB design combined over years. The data of 2004-05 were analyzed in RCB design. Baby trials data were tested by two-tailed paired t-test. Survey data were compiled in Excel sheet. Adoption data of varieties were converted into percentage. Impacts were estimated by the difference of two survey data. Some survey data were analyzed by Chi-square test.

\section{Results and Discussion}

\section{Identify farmers' need}

Farmers' expected a good number of characters in their wheat varieties during PRA. Among those, top six characters, prioritized according to total scores and ranked through matrix system as shown in Fig. 1. High yield got the highest score and ranked $1^{\text {st }}$ followed by easy threshability (Baksh et al., 2003). Importance of these two characters was statistically similar but significantly

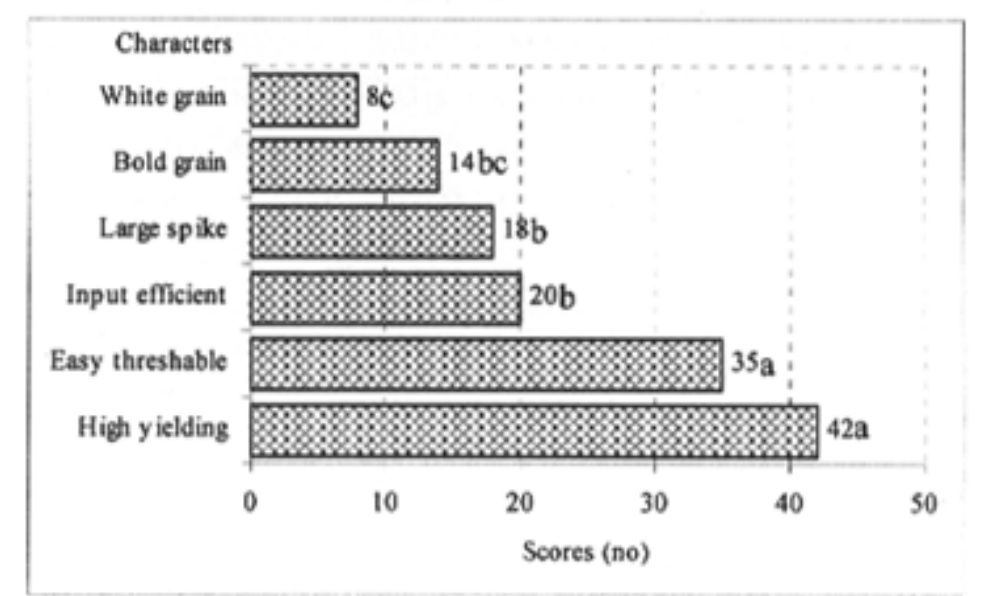

Fig. 1. Farmers' expected characters for wheat varieties at Dinajpur, Bangladesh (Lettering was made according to $\chi 2$ probability)

higher than others. Threshing was important problem because of labour shortage at wheat harvesting period. At that time labourers were engaged in seeding jute, transplanting Aus, weeding boro and some other activities. Besides those, premonsoon rains at wheat harvesting force farmers to rapid harvesting and threshing in some years. Though, wheat threshers were available, but these were 
not adequately adopted by the farmers. The importance of this problem might reduce remarkably when wheat threshers would be adopted by the farmers. The $3^{\text {rd }}$ important character was input efficiency of the varieties. Most of the farmers of Bangladesh are small and poor. They do not have enough money to use for recommended inputs. The $4^{\text {th }}$ important character of the farmers' identified was large spike. Large spike is attractive to look at and produce more grains/spike, thereby increase yield. The next important character was bold grains followed by white colour. Importance of grain colour was significantly lower than other characters except bold grain. The farmers told that, when yield is high, then grain size and weight is not very important to them.

\section{Experimentation in farmers' fields Mother trial}

The genotypes differed significantly for yield and farmers' overall preference (FOP) scores in MT, both at farmers' fields and on-station (Table 1). The highest mean yield in two years at farmers' fields was obtained by Shatabdi (4063 kg/ha) followed by BAW 1008 (3942 kg/ha). The yield of both these genotypes was statistically similar. The $3^{\text {rd }}$ highest yield was produced by BAW 1004 (3861 kg /ha) followed by BAW 1006 (3810 kg/ha) and Kanchan (3704 kg/ha). The lowest yield was produced by BAW 966. At on-station, yield was higher than farmers' fields. The highest mean yield at research station was produced by BAW 1008 (5325 kg/ha) followed by BAW $1006(5142 \mathrm{~kg} / \mathrm{ha})$. Shatabdi produced the $4^{\text {th }}$ highest yield. Kanchan was the lowest yielder followed by BAW 966. $\neq$

Table 1. Interaction effect of genotype $x$ year on yield and farmers' overall preference (FOP) scores at farmers' field and on-station at Dinajpur, Bangladesh.

\begin{tabular}{c|ccc|c|c|c|c|c|c|c}
\hline \multirow{2}{*}{ Genotype } & \multicolumn{3}{|c|}{ Yield at farmers' field } & \multicolumn{3}{c|}{ Yield at on-station } & \multicolumn{2}{c}{ FOP scores with rank } \\
\cline { 2 - 10 } & $2002-$ & $2003-$ & Mean & $\begin{array}{c}2002- \\
03\end{array}$ & $\begin{array}{c}2003- \\
04\end{array}$ & Mean & $\begin{array}{c}2002- \\
03\end{array}$ & $\begin{array}{c}2003- \\
04\end{array}$ & Mean \\
& 03 & 04 & & & 03 & 03 & \\
\hline Kanchan $\S$ & 3604 & 3803 & 3704 & 4000 & 4483 & 4242 & $5.9(5)$ & $6.2(5)$ & 6.1 \\
& $(5)$ & $(5)$ & $(5)$ & $(6)$ & $(6)$ & $(6)$ & & & $(5)$ \\
Shatabdif & 4088 & 4037 & 4063 & 4950 & 4950 & 4950 & $7.4(1)$ & $7.0(3)$ & 7.2 \\
& $(1)$ & $(2)$ & $(1)$ & $(5)$ & $(2)$ & $(4)$ & & & $(2)$ \\
BAW 966 & 3292 & 3775 & 3534 & 5150 & 4500 & 4825 & $5.4(6)$ & $5.8(6)$ & 5.6 \\
& $(6)$ & $(6)$ & $(6)$ & $(4)$ & $(5)$ & $(5)$ & & & $(6)$ \\
BAW 1004 & 3804 & 3917 & 3861 & 5250 & 4750 & 5000 & $6.9(3)$ & $7.0(3)$ & 7.0 \\
& $(2)$ & $(4)$ & $(3)$ & $(3)$ & $(4)$ & $(3)$ & & & $(4)$ \\
BAW 1006 & 3692 & 3927 & 3810 & 5400 & 4883 & 5142 & $6.7(4)$ & $7.4(2)$ & 7.1 \\
& $(4)$ & $(3)$ & $(4)$ & $(2)$ & $(3)$ & $(2)$ & & & $(3)$ \\
BAW 1008 & 3775 & 4108 & 3942 & 5600 & 5050 & 5325 & $7.2(2)$ & $7.5(1)$ & 7.4 \\
& $(3)$ & $(1)$ & $(2)$ & $(1)$ & $(1)$ & $(1)$ & & & $(1)$ \\
\hline LSD(0.05) & \multicolumn{7}{c}{267} & 164 & \multicolumn{7}{c}{327} & 294 & 0.48 & 0.33 \\
\hline
\end{tabular}

$\S=$ Widely adapted check variety; $\neq=$ Released variety. Figures within parenthesis indicated ranks. Rank 1 was the best and 6 was the worst 


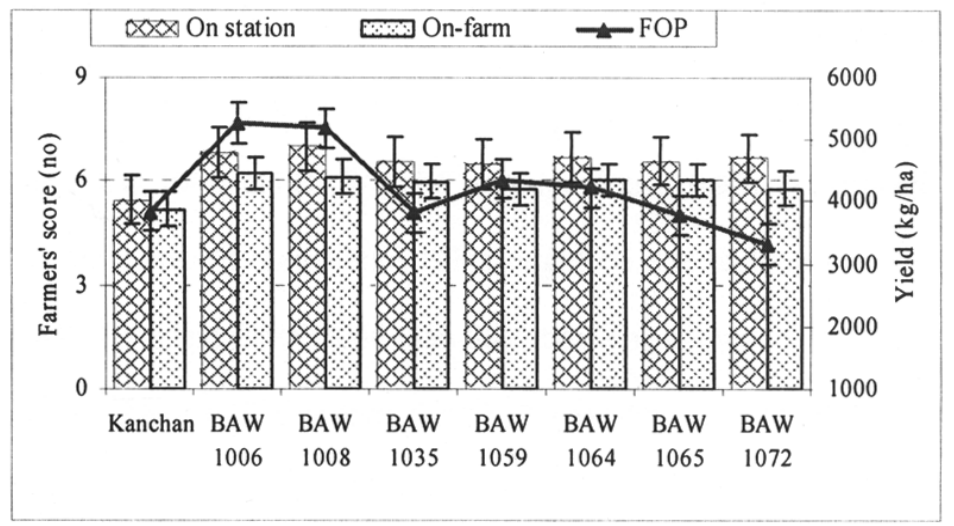

Fig. 2. Yield and FOP scores for the genotypes of mother trials in 2004-05 at Dinajpur, Bangladesh.

In 2004-05, only three genotypes were common to that of previous years. In this year, BAW 1008 again produced the highest yield at on-station and $2^{\text {nd }}$ highest yield at farmers' field (Fig. 2). RAW 1006 was the $2^{\text {nd }}$ highest and the highest yielder at on-station and farmers' field, respectively. The $3^{\text {rd }}$ highest yield was produced by BAW 1064 at on-station and BAW 1065 at farmers' field. In this year, Kanchan produced the lowest yield in both growing situations.

The interaction effect of genotype and year on yield revealed that Shatabdi was the highest yielder at farmers' field in 2002-03 but BAW 1008 was the highest in 2003-04. However, at on-station experiment, BAW 1008 was the highest yielder in both the years (Table 1). At farmers' field, the $2^{\text {nd }}$ highest yielder was BAW 1004 in 2002-03 and Shatabdi in 2003-04. But at on-station, BAW 1006 was the $2^{\text {nd }}$ highest yielder in 2002-03 and Shatabdi in 2003-04. The results indicated that there was some interaction between genotypes and years. But, it was clear that BAW 1008 was good yielder in all growing situations and years followed by Shatabdi and BAW 1006. So, it can be concluded that the performance of these genotypes were stable and these genotypes perhaps would be widely adapted. Wide adaptation is important and there was no evidence that selection for broad adaptation was a poor strategy when breeding even for marginal environments (Witcombe, 1989 and Virk et al., 1996). BAW 1004 also produced good yield in all situations. Kanchan and BAW 966 was consistently poor yielder. Yield difference at farmers' field and on-station was probably due to difference in input use.

The farmers' overall preference data indicated that the highest preference score was got by Shatabdi in 2002-03 and BAW 1008 in 2003-04. Here, farmers' 
preference score was related to yield. The $2^{\text {nd }}$ highest score was obtained by BAW 1008 in 2002-03 and BAW 1006 in 2003-04. These genotypes were $3^{\text {rd }}$ in yield in the respective years. On the other hand, Shatabdi was $3^{\text {rd }}$ in preference rank in 2003-04, but it was $2^{\text {nd }}$ in yield in the same year. In farmers mean preference ranking, BAW 1008 was $1^{\text {st }}$ followed by Shatabdi and BAW 1006, whereas, in mean yield, these genotypes were $2^{\text {nd }}, 1^{\text {st }}$ and $4^{\text {th }}$, respectively. The results indicated that BAW 1008 and BAW 1006 were more preferred and Shatabdi was less preferred by the farmers' comparative to their yields. This might be due to longer spike, stronger stem and bolder grains of BAW 1008 and BAW 1006 than Shatabdi. The average 1000-grain weight of BAW 1008 and BAW 1006 was 9 and 4g higher than Shatabdi. The scores on FOP in 2004-05 also confirmed the results of other two years. BAW 1059 got $3^{\text {rd }}$ preference by the farmers next to BAW 1008 and BAW 1006, but in yield, its position was $7^{\text {th }}$. On the other hand, BAW 1065 was the $3^{\text {rd }}$ highest yielder but it was $6^{\text {th }}$ in farmers preference rank (Fig. 2). BAW 1059 had bolder grains than BAW 1065. So, during scoring, farmers have considered other characters like bold grains, large spike, strong stem, earliness, etc., along with yield (Rashid et al., 2004). Therefore, breeders have to emphasize farmers' attitudes during selection; otherwise their varieties may not be well accepted by the users. Joshi et al, (1995) also reported that in addition to grain yield, farmers also consider other parameters like growing period, plant height, threshability, milling recovery, taste and other characters of rice. Farmers contribute in goal setting in identifying traits and in providing a testing system that is multi-farmers, multi-locations and allow the trade-off between many traits (Joshi et al., 2002).

\section{Baby trials}

The average yield difference of the genotypes of baby trials from check variety Kanchan presented in Fig. 3 revealed that BAW 966 and BL 1473 produced significantly lower yields than Kanchan in 2002-03. In 2003-04, the tested entries produced statistically similar yield to Kanchan, however, there was some numerical difference. The highest yield was produced by BAW 1008 followed by BAW 1006 in 2004-05 and the yields of these genotypes were significantly higher than Kanchan. Shatabdi, BAW 1004 and BAW 1027 also produced higher

yields than Kanchan. The results also indicated that the yield of BAW 1006 has consistently increased every year in BT. Though the yield increase of BAW 1008 was low in 2003-04 but it was very high in 2004-05. The results of baby trials were in agreement with that of mother trials. So, both types of trials were equally important in selecting genotypes. However, baby trial is simpler and needs less cost to execute. BAW 1004 had good yield and FOP scores in MT, but, it was rejected by the researchers due to its lodging susceptibility. Though, farmers' 
possess the ability of selecting genotypes and species to suit their

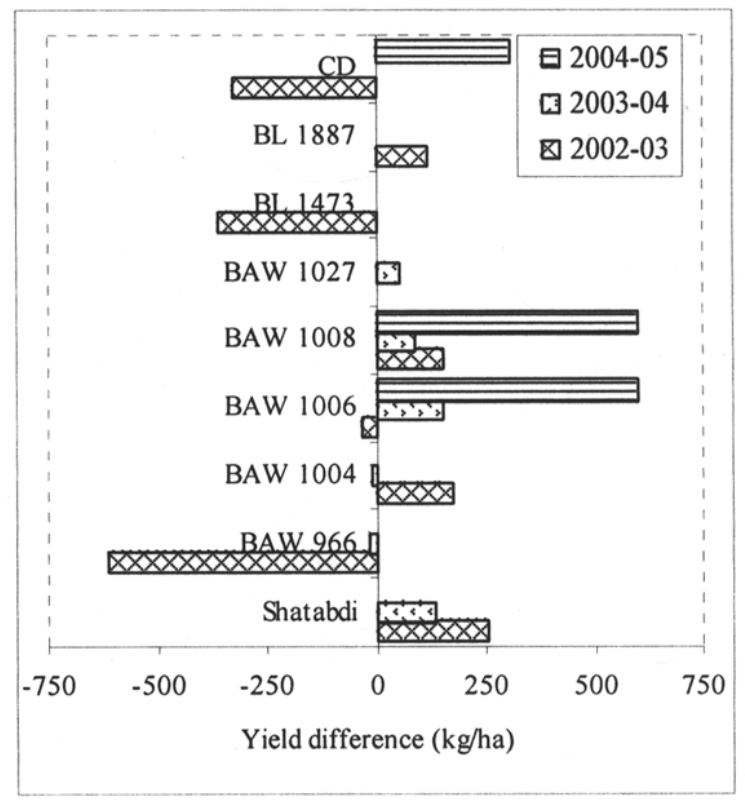

Fig. 3. Yield difference of the genotypes of baby trials from Kanchan at Dinajpur, Bangladesh.

environments, resources and other quality and consumer requirements (Hardon, 1995), still, they might have some deficiency in selecting for specific traits, especially disease susceptibility and some others due to their inadequate scientific knowledge. So, science based knowledge (researchers' knowledge) and local knowledge system (farmers' knowledge) must be optimized in agricultural research and developmental process (Haverkort, 1991), which the PVS approach is doing. BAW 966 was lower yielder and less preferred by the farmers, still, it was released as variety because of its better bread making quality. It has high protein, strong gluten, and high bread loaf volume. The variety also produced the highest yield among the genotypes tested in late seeding conditions at 16 multilocation trials (MLT) of eight regions across the country in national breeding programme. The survey data collected by house-hold level questionnaire (HLQ) from baby trials revealed that Shatabdi, BAW 966, BAW 1006, BAW 1008 and Kanchan were equally preferred by the farmers of Dinajpur in 2003-04 for Chapati quality. No body liked BAW 1027 for Chapati. The data of 2004-05 also indicated that $45 \%$ farmers preferred BAW 1006, 35\% preferred BAW 1008, and 
only 20\% preferred Kanchan for Chapati quality. Shatabdi was not tested this year. As most of the wheat in Bangladesh is consumed as Chapati, it was very important to test the genotypes for Chapati quality. PVS ensures that all farmersrelevant traits are evaluated. It is particularly efficient when important post harvest quality traits that are costly and difficult to assess in the laboratory can be selected by farmers. Selection for such traits is most appropriate because farmers and their families are the ultimate judges of quality in their conditions (Witcombe and Virk, 1997). In PVS approach, the farmers and their families assess all major parameters relevant to farmers, for example, taste, quality, market value, and not just the limited set of characters measured in traditional plant breeding trials (Joshi and Witcombe, 1996).

For next year's cultivation BAW 1008, Shatabdi, and BAW 1006 were the most preferable varieties by all the sampled farmers of the PVS villages of Dinajpur. Good plant type and Bipolaris leaf blight (BpLB) tolerance of all the three genotypes, higher yields of Shatabdi, high yield, strong stem, bold grains and large spikes of BAW 1008 and high yield, large and shiny grains of BAW 1006 were the major causes for their preference. On the other hand, small grains and low yield of BAW 966 and poor yield and BpLB susceptibility of Kanchan was the main disliking factors to the sampled farmers.

\section{Scaling-up seed dissemination and varietal diversity}

Only $20 \mathrm{~kg}$ seeds of released variety Shatabdi were supplied to each of the 20 farmers of two villages in 2002 and $20 \mathrm{~kg}$ to each of 10 farmers in $3^{\text {rd }}$ village through PVS programme in 2003 for scaling-up seed dissemination. Farmers seeded and grew the crop in their own management. From that small quantity (600 kg), 110 tons seeds were produced and prserved by the farmers of three villages in 2004-05. The seed spread pattern demonstrated that 20 farmers disseminated seeds to other 50 farmers and PVS programme supplied to 10 farmers of 3rd villages in 2003. So, seed reached 60 farmers in 2003. In 2004, seeds reached 138 farmers from farmer-source only (Fig. 4) and that number was $47 \%$ wheat farmers of PVS villages. From the product of those seeds not only $57 \%$ wheat area was seeded by Shatabdi in 2005-06 at three villages (Fig. 4), they also sold those seeds at higher price (Tk. 30/kg) than the Government fixed price (Tk. 22/kg) and earned a good amount of money. 


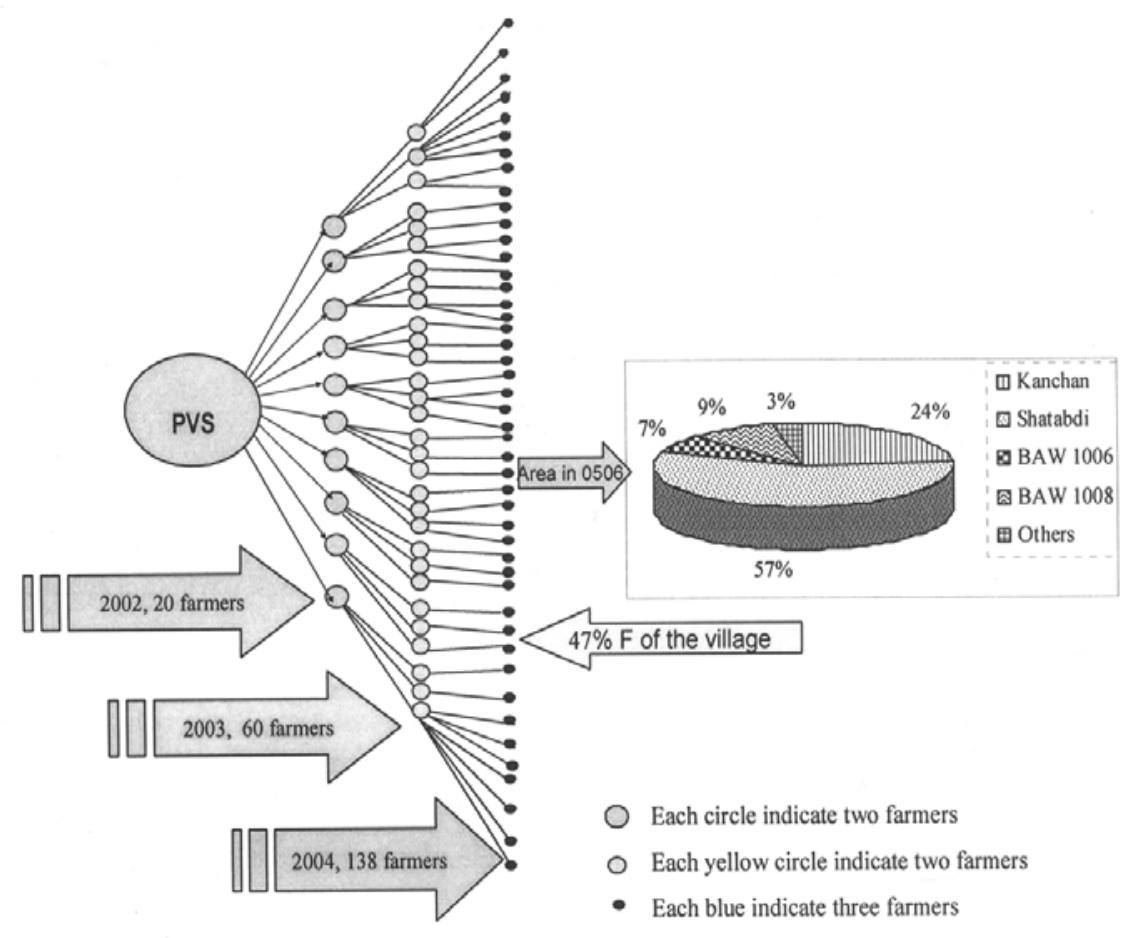

Fig. 4. Seed dissemination from farmers to farmers from 2002 to 2004 (left) and area covered by different varieties in 3 PVS villages of Dinajpur in 2005-06.

Area of Kanchan came down from $100 \%$ (in 2002) to $24 \%$ in $2005-06$. The newly released varieties BAW 1006 and BAW 1008 covered 7 and 9\% wheat area, respectively, of the PVS villages of Dinajpur. The farmers'selected varieties were so popular to the farmers that all of them collaborated with baby and mother trials preserved the whole quantity of seeds obtained from their trials. Other varieties (Protiva, Sourav, and Gourab) occupied 3\% wheat areas of the villages. Probably, that was the first time in wheat cultivation in Bangladesh, when seven varieties were grown in same villages by the farmers themselves. This has increased the genetic diversity of cultivated wheat and reduced the risk of disease epidemic. Increase biodiversity is very useful since pathogens and pests are exposed to particular genotypes for less time and have less chance to overcome host-plant resistance (Witcombe et al., 1996). Varietal diversity is also advisable to address varied physical environments, socio-economic conditions and the needs of farmers. Widespread adoption of participatory methods at national level will almost certainly increase the replacement rate of old cultivars, so that the 
average age of cultivars grown by farmers will be reduced and biodivesity over time will be increased (Witcombe et al., 1996).

\section{Conclusion}

Results of PVS research in Dinajpur, Bangladesh indicated that BAW 1008, Shatabdi, and BAW 1006 consistently produced higher yields both in mother and baby trials. These genotypes also got high farmers' overall preference (FOP) scores. They had better Chapati quality and farmers expressed their opinion to cultivate those in the following years. Baby trial was found equally effective to mother trial but that was much easy to conduct and less expensive to execute. Farmers' emphasized more on simultaneous selection rather than empirical selection on yield only. Farmers'selected varieties were extending very rapidly and increasing varietal diversity. Farmers to farmers seed transfer was found very effective in scaling-up seed transfer and increase varietal diversity.

\section{Acknowledgements}

The authors are grateful to Dr. G.O. Ferrara, Dr. J.R. Witcombe, Dr. D.S. Virk and Dr. K.D. Joshi for providing funds and giving suggestions and guidelines in conducting the research during the whole project period. The authors would like to thank all the participating farmers and extension officials of Dinajpur District of Bangladesh for their cooperation in making the approach successful.

\section{References}

Baksh, E., M.H. Rashid and M.G. Rabbani. 2003. Participatory rural appraisal of PVS site Daulatpur, Thakurgaon, Dinajpur, Bangladesh. A PRA report of Wheat Research Centre, Bangladesh Agricultural Research Institute, Nashipur, Dinajpur, pp.31.

Bellon, M.R. 2001. Participatory Research Methods for Technology Evaluation. A Manual for Scientist Working with Farmers. Mexico, D. F. CIMMYT, pp. 93.

Bodruzzaman, M., J.G. Lauren, J.M. Duxbury, M.A. Sadat, R.M Welch, N.E. Elahi and C.A Meisner. 2004. Increasing wheat and rice productivity in the sub-tropics using micronutrient enriched seed. In Micronutrients in South and South-east Asia. Eds by P. P. Anderson, K. Junoo, Tuladhar, B. Krishna karki and Surya L, Maskey. Proc. of an International Workshop, held at 8-11 Sept, 2004, Kathmandu, Nepal: 17-198.

Grisley, W. and M. Shamambo. 1993. An analysis of adoption and diffusion of Carioca beans in Zambia resulting from an experimental distribution of seed. Expl. Agriculture 29:379-386.

Hardon, J. 1995. Participatory plant breeding. The outcome of a workshop on participatory plant breeding. Issues in Genetic Resources No. 3. October 1995. Rome, Italy, international Plant Genetic Resources Institute 
Haverkort, B. 1991. Farmers experiments and participatory technology development. In Joining Farmers Experiments: Experience in Technology Development. Eds. B. Haverkort, J. Vander Kamp \& A. Waters-Bayer). London, UK: Intermediate Technology Publications.

Joshi, K.D., R.B. Rana, M. Subedi, K.B. Kadayat \& B.R. Sthapit. 1995. Effectiveness of participatory testing and dissemination programme: a case study of Chaite Rice in the western hills of Nepal. LARC working paper No. 95/49. Pokhara, Nepal: Lumble Agricultural Research Centre.

Joshi, A \& J.R. witcombe. 1996. Farmer participatory crop improvement. II. Participatory Varietal Selection: a case study in India. Expl Agric 32:461-477.

Joshi, K.D., B.R. Sthapit., M. Subedi \& J.R. Witcombe. 2002. Enhancing on-farm varietal diversity through participatory varietal selection: a case study of Chaite Rice in Nepal. Expl Agric. 33:335-344.

Rashid, M.H., D.B. Pandit, M.M. Islam \& M.M. Rahman. 2004. Research Report on Participatory research to increase the Productivity and sustainability of wheat based cropping at Dinajpur, Bangladesh. Report presented at the $2^{\text {nd }}$ Regional Review and Planning Workshop of PVS project, held at Hotel View-Bhirikuti, Olitpur, Nepal during 14-18 June 2004.

Sufian, M.A. 2005. Sustainable wheat production in Bangladesh in relation to climate change. A Key note paper presented at the workshop on "Sustainable Wheat production, held at BRAC Centre Inn, Dhaka on October 2005.

Virk, D.S., A J.P. Packwood and J.R. Witcombe. 1996. Plant breeding, varietal testing and popularization and research linkage. Paper presented at ODA/ICAR workshop on recognizing research for rain fed farming. CRIDA, Hyderabad. 11-15 Sept. 1995.

Witcombe, J.R. 1989. variability in the yield of pearl millet hybrid and varieties in India and Pakistan. In Variability in Grain Yields. Implications for Agricultural Research and Policy in developing Countries. Eds. J.R. Anderson and P. B. R. Hazel Baltmore: John hopkins University Press. In Association with the International Food Policy Research Institute, pp 205-220.

Witcombe, J.R, A. Joshi, K.D. Joshi \& B.R. Sthapit. 1996. Farmers participatory crop improvement. I. varietal selection and breeding methods and their impacts on biodiversity. Expl Agric 32:445-460.

Witcombe, J.R. and D.S. Virk. 1997. New directions in public sector variety testing. In new seeds and old laws: Regulatory reforms and the diversification of national seed system. Eds. Robert Tripp: 59-87. London, UK: intermediate Technology Publications.

Witcombe, J.R. 1999. Do farmer participatory methods apply more to high potential areas than to marginal ones. Outlook on Agriculture 28: 43-49.

Witcombe, J.R. 2002. A Mother and Baby trial system. Witcombe, J.R., Parr, L.B and Atlin, J.R. (eds.). 2002. Breeding rain fed rice for drought-prone environments: Integrating conventional and participatory plant breeding in South and South-east Asia: Proc. of a DFID Pl. Sci. Res. Prog./IRRI Conference, 12-15 March 2002, IRRI, Los Banos, Manila, Philippines, pp. 104. 
PANDIT et al. 